\title{
Analysis of the profile of competencies obtained in undergraduate courses in life sciences and the expected profile of competencies of the project professional
}

Claudia Ota-Tsuzuki ${ }^{1}$, Fundação Carlos Alberto Vanzolini

Ana Lucia Figueiredo Facin², Universidade de São Paulo, Escola Politécnica da USP, Dpto. de Engenharia de Produção João Walter Saunders Pacheco do Vale ${ }^{3}$, Universidade de São Paulo, Escola Politécnica da USP, Dpto. de Engenharia de Produção Marly Monteiro de Carvalho ${ }^{4}$, Universidade de São Paulo, Escola Politécnica da USP, Dpto. de Engenharia de Produção

\section{RESUMO}

Projetos são utilizados cada vez mais para atingir objetivos de negócios, por isso a demanda por profissionais de projeto vem crescendo, assim como o interesse pelas competências a serem desenvolvidas. Este trabalho teve como objetivo traçar o perfil de competências para o trabalho com projetos, esperado dos alunos da área de ciências da vida ao final da graduação, e o perfil esperado do profissional de projetos pela perspectiva de profissionais de projetos da área de ciências da vida. O método utilizado foi o de estudo de caso com entrevistas, análise qualitativa do material coletado e das diretrizes propostas pelo MEC para os cursos de graduação de ciências da vida. Concluiu-se que algumas das competências essenciais para trabalhar com projetos deveriam ser desenvolvidas durante os cursos de graduação. As entrevistas chamam atenção para a importância de preparar o aluno de graduação para o trabalho com projetos, necessidade cada vez mais evidente. Ao comparar as diretrizes curriculares e o conteúdo das entrevistas, percebe-se a distância entre o que é proposto pelas diretrizes e o que é realmente ministrado na graduação da área de ciências da vida.

Palavras-chave: Profissional de projetos. Gerentes de projetos. Competências. Área de ciências da vida. Graduação. Diretrizes curriculares.

\section{ABSTRACT}

Organizations have been using projects to reach their business goals, thus the demand for project professionals has been increased, and the interest in their competencies as well. This study aimed to determine the profile of competency to work in projects that students from the life science field are expected to obtain during their undergraduate studies as well as investigate the expected profile of competency from the perspectives of project professionals. The chosen method was a case study with interviews, and qualitative analysis of the collected material, and the curricular guidelines for the programs from life science area suggested by MEC. The data revealed that the curricular guidelines feature some of essential competencies to work with projects that should be acquired during the undergraduate studies. The interviews highlighted the importance of preparing the undergraduate students for working with projects, an increasingly evident tendency in corporations nowadays. By comparing the curricular guidelines and the interviews, the distance between the curricular guidelines suggested by MEC and the real content that is presented to undergraduate students from life science area can be perceived.

Keywords: Project professional. Project manager. Competencies. Life science area. Graduate course. Curricular guidelines.

1. clauotat@gmail.com; 2. Rua Pedro Cacunda, 344 - apto 53, São Paulo - SP, 02046-090: affacin@gmail.com ou afacin@usp.br; 3.waltrk@gmail.com; 4. marlymc@usp.br

OTA-TSUZUKI, C.; FACIN, A.L.F.; VALE, J.W.S.P.; CARVALHO, M.M. Análise do perfil de competências obtido em cursos de graduação em ciências da vida e o perfil de competências esperado do profissional de projetos. GEPROS. Gestão da Produção, Operações e Sistemas, v. 15, n. 1, p. 129 - 150, 2020.

DOI: $10.15675 /$ gepros.v15i1.2361
Editor Responsável: Prof. Dr. Hermes Moretti Ribeiro da Silva 
Análise do perfil de competências obtido em cursos de graduação em ciências da vida e o perfil de competências esperado do profissional de projetos

\section{INTRODUÇÃO}

O setor de ciências da vida compreende todas as organizações que operam nas áreas de biotecnologia, farmacêutica, tecnologias biomédicas, processamento de alimentos, tecnologias do meio ambiente e equipamentos médicos. Estas organizações incluem instituições acadêmicas, indústrias de pequeno e médio porte, empresas globais e governamentais (BEUKERS, 2010).

Tradicionalmente, pesquisas básicas e aplicadas eram consideradas atividades de naturezas distintas. Entretanto, com o advento de novas tecnologias de informação e comunicação e da biotecnologia, a partir dos anos 80, esta visão vem mudando, com a valorização da aplicação dos conhecimentos científicos em produtos concretos (OOSTERLINCK; DEBACKERE; CIELEN, 2002). Acompanhando este cenário, ocorreu uma progressiva diversificação dos tipos de atividades que empregam doutores, e que exigem destes profissionais, novas competências e papéis (VELHO; RAMOS, 2013).

Os trabalhos baseados em projetos antes restritos às áreas de TI (Tecnologia da Informação), construção e engenharia, atualmente vem sendo empregados em vários setores, inclusive na área da saúde. Embora o número de profissionais desta área que trabalha com projetos seja pequeno, o risco de fracassos entre estes profissionais é grande, em parte por conta do treinamento em gestão de projetos não estar presente no conteúdo curricular e em parte porque frequentemente ele não é claramente discutido na literatura da área de saúde (CHIOCCHIO, RABBAT, LEBEL, 2015).

Monteiro, Almeida Junior e Wajnzstejn (2014), ao questionarem se pesquisadores de alta produtividade possuem conhecimentos de gestão de projetos, argumentam que estes provavelmente não tenham estes conhecimentos, mas que em geral, possuem características de potenciais gerentes, tais como capacidade de identificar riscos e seus impactos ao tomar decisões, habilidades de construir e manter relações, comunicação, e criar um relacionamento de confiança com os gerentes de projetos.

$\mathrm{Na}$ área de ciências da vida, os projetos são complexos uma vez que não existe uma clareza sobre "como" e "o que" será alcançado com o projeto. Além disso, em geral, estes estudos são realizados em conjunto com um grande número de parceiros em múltiplas disciplinas ao longo de todas as etapas dos mesmos (BEUKERS, 2010). 
Análise do perfil de competências obtido em cursos de graduação em ciências da vida e o perfil de competências esperado do profissional de projetos

Payne et al. (2011) aplicaram técnicas de gestão de projetos ao executarem uma pesquisa na área de saúde e concluíram que a gestão de projetos contribuiu substancialmente para a entrega do projeto, e ainda que os participantes usariam deste recurso em projetos futuros. Concluíram ainda que o uso de tais técnicas pode beneficiar a gestão e as saídas científicas (resultados) em projetos na área de pesquisa e saúde. Chiocchio, Rabbat e Lebel (2015) também concluíram que embora não faça parte do currículo de formação do profissional de saúde, a aplicação de técnicas de gestão de projetos é essencial para a melhoria nas organizações de atenção à saúde.

Thomas e Mengel (2008) afirmaram que a educação em gestão de projetos era um campo relativamente novo, e que muito ainda havia que aprender com sua "irmã mais velha" a educação em Gestão. Segundo estes mesmos autores, em projetos complexos, mais do que a transferência de conhecimento, são necessários modelos educacionais que suportem e incentivem mudança contínua, criatividade, reflexão criativa, uma rede de contatos organizada, comunicação virtual e intercultural, capacidade de lidar com incertezas e vários parâmetros de referências, para aumentar o autoconhecimento e a habilidade de construir times de alta performance.

Neste contexto, o objetivo geral deste trabalho é analisar o perfil de competências esperado dos profissionais de projetos com formação na área de ciências da vida sob a perspectiva de gerentes e profissionais de projetos atuando em diversas áreas. $\mathrm{O}$ objetivo secundário é mapear competências associadas à gestão de projetos que se espera que os profissionais da área de ciências da vida tenham ao final dos cursos de graduação.

\section{REFERENCIAL TEÓRICO}

\subsection{Competência em gestão de projetos}

A gestão de projetos surgiu como uma prática muito utilizada pelas organizações para alcançar seus objetivos de negócios. Como nas organizações uma parte cada vez maior de suas atividades são definidas como projetos, a demanda por profissionais com competência para gestão de projetos tem crescido, e assim também o interesse pelas competências do gerente de projetos (CRAWFORD, 2005).

Edum-Fotwe e McCaffer (2000) investigaram o desenvolvimento das competências do gerente de projetos. Ao avaliar vários aspectos do desenvolvimento do gerente de projetos, 
Análise do perfil de competências obtido em cursos de graduação em ciências da vida e o perfil de competências esperado do profissional de projetos

descobriram que o desenvolvimento acadêmico, embora falho em alguns assuntos técnicos durante a graduação, poderia ser compensado com módulos de cursos ou mesmo cursos de período integral, tais como programas de pós-graduação, que são tidos como de grande importância para o exercício das funções de gerente.

Dainty et al. (2005) estudaram as competências essenciais associadas aos gerentes de projeto, e concluíram que o autocontrole e a liderança são as competências mais características desta função. Segundo os autores, esta informação não foi surpreendente já que, em tal função, os gerentes são responsáveis por montar, desenvolver e manter a equipe, além disso, precisam agir prontamente em situações de estresse.

A definição, avaliação e desenvolvimento de competências para gerente de projetos são abordados pelo PMI (2007) no "The Project Manager Competency Development (PMCD) Framework". De acordo o PMI (2007), a competência do gerente de projetos consiste de 3 dimensões distintas: 1) Conhecimento - conhecimento técnico para a realização das atividades em projetos; 2) Desempenho - como o gerente aplica os conhecimentos de modo a atingir os objetivos do projeto; e 3) Pessoal - como o gerente se comporta frente as atividades no ambiente de projetos, suas atitudes, e características principais de personalidade. Este modelo de avaliação é complementado pelos requisitos de desempenho da indústria e das organizações (Figura 1).

Figura 1 - Dimensões das competências do gerente de projetos.

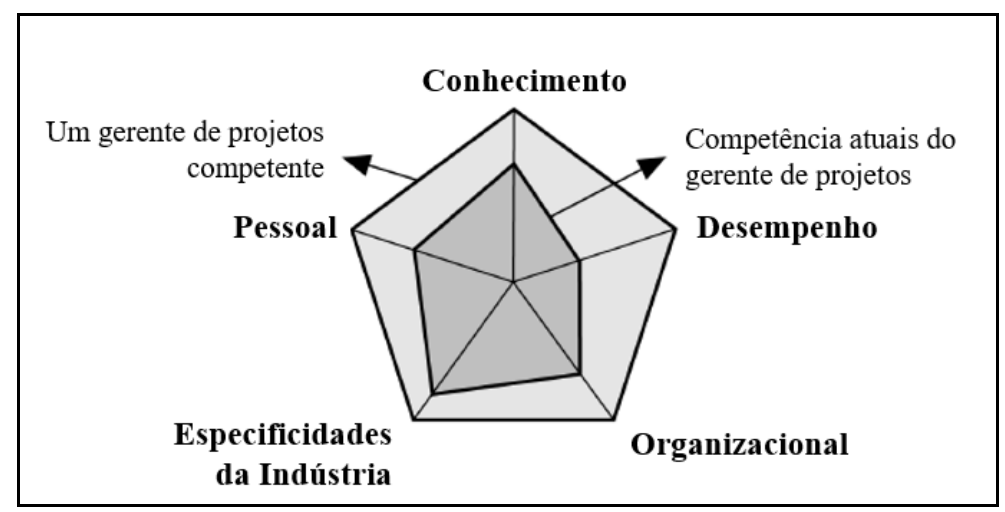

Fonte: Adaptado de PMI (2007).

O IPMA (2006) cita ainda outra dimensão, a da competência contextual, isto é, competência para conduzir o projeto de acordo com os objetivos da organização, do portfólio, e do programa, dentro dos quais está inserido o projeto (Figura 2). 
Análise do perfil de competências obtido em cursos de graduação em ciências da vida e o perfil de competências esperado do profissional de projetos

Figura 2 - Competências do gerente de projetos.

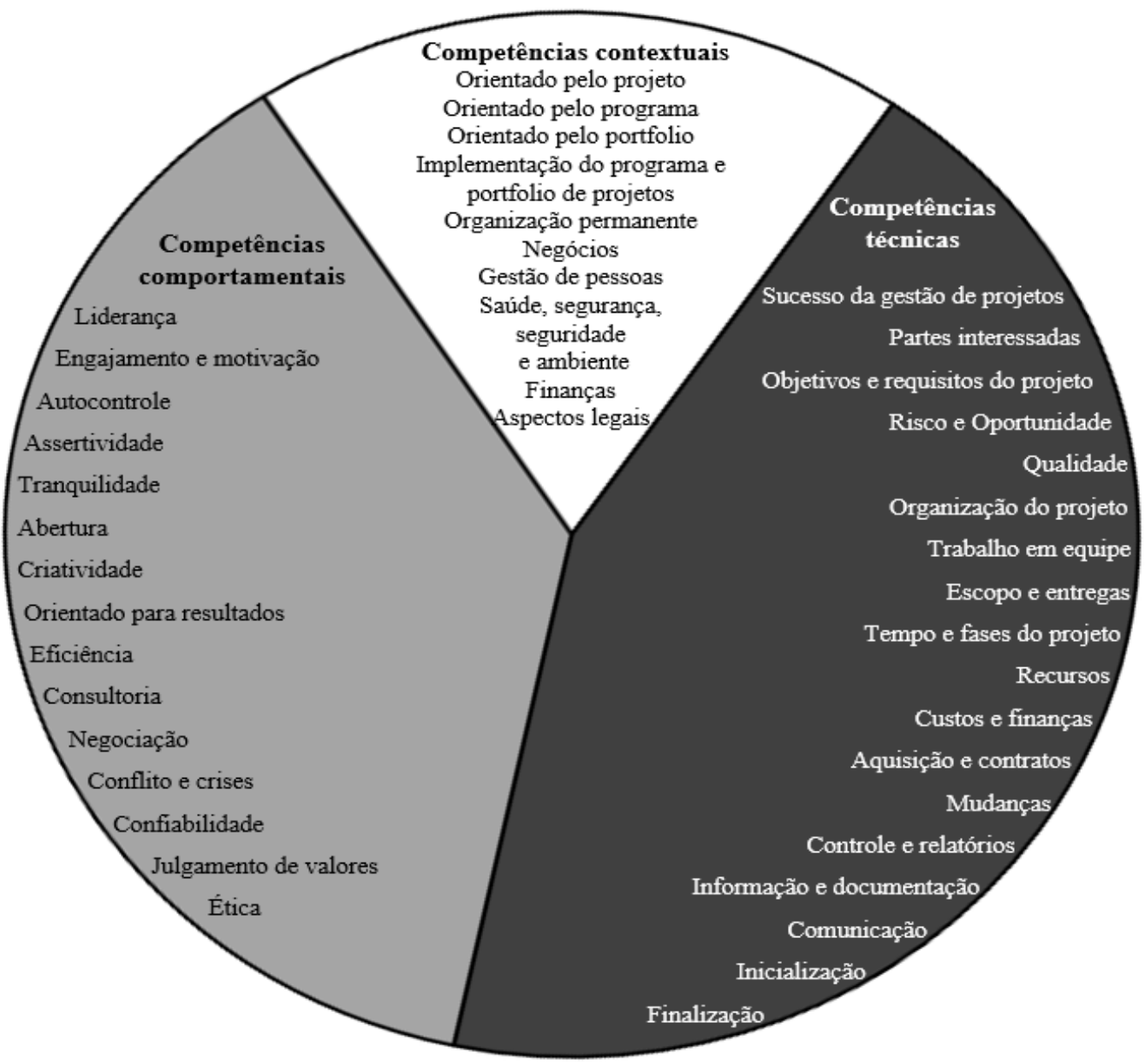

Fonte: Adaptado de IPMA (2006).

As competências para a gestão de projetos também foram estudadas por Rose et al. (2007), que mapearam as seguintes competências: técnica, para processos, para trabalhar em grupo, para estabelecer relacionamentos com cliente, para negócios, pessoais para lidar com diferentes contextos, e para administrar as incertezas. Já Stevenson e Starkweather (2010) identificaram alguns soft skills como competências críticas: liderança, comunicação em múltiplos níveis, habilidades verbais e escritas, atitude, habilidade para lidar com ambiguidades e mudanças.

Geoghegan e Dulewicz (2008), por sua vez, exploraram como hipótese a existência de uma relação estatisticamente significativa entre a competência de liderança do gerente de projetos e o sucesso do projeto. Para a pesquisa foi proposto um questionário que investiga as dimensões de liderança (Leadership Dimension Questionnaire - LQD) que revelou as 3 
Análise do perfil de competências obtido em cursos de graduação em ciências da vida e o perfil de competências esperado do profissional de projetos

competências mais encontradas, que são: consciência de liderança; sensibilidade; e autoconhecimento; todas competências emocionais. O questionário que investigou as dimensões de sucesso do projeto (Project Success Questionnaire - PQS) revelou as dimensões de liderança que contribuem para o sucesso do projeto e que possuem uma estreita relação com o sucesso na solução de problemas, entre elas: gestão de recursos, empoderamento, desenvolvimento e motivação.

Ao analisarem o perfil da competência para liderança de gerentes de projetos bemsucedidos, Müller e Turner (2010) verificaram que este perfil difere de projeto para projeto; e independente da área de atuação. Suas pesquisas indicaram valores altos para a dimensão de Quociente de Inteligência (pensamento crítico) e para 3 dimensões de Quociente Emocional (influência, motivação e consciência). Os autores ainda sugerem que as competências de liderança devem ser levadas em consideração ao designar um gerente para um determinado projeto; e que o treinamento e desenvolvimento destes gerentes não deveriam focar somente nos conhecimentos e habilidades técnicas, mas também no desenvolvimento das competências para liderança.

Clements e Gido (2013) destacaram que o gerente de projetos é um elemento chave para o sucesso de um projeto, e para tanto, deve dominar um conjunto de habilidades e competências que servirão de inspiração para a equipe e para conquistar os clientes. Além disso, devem ter liderança forte, habilidade de desenvolver pessoas, habilidade de comunicação, competência de negociação e de gestão de tempo.

Ahsan, Ho e Khan (2013) compararam as competências necessárias à um gerente de projetos segundo a literatura e as competências exigidas pelas indústrias através dos anúncios de empregos, e concluíram que além das habilidades para gestão da comunicação, assuntos técnicos e partes interessadas, gerenciamento de custo e tempo também são exigidas. Quanto ao conhecimento, a formação educacional e as certificações são os itens mais requisitados. Além disso, as habilidades estão orientadas para a obtenção de resultados. Os mesmos autores analisaram ainda diferenças entre os múltiplos setores e entre diferentes países, e concluíram que as competências exigidas diferem entre os países e entre as indústrias pesquisadas, e que estas diferenças dependem da função do gerente de projetos dentro da empresa.

O PMI (2014) define competência como, a habilidade e a capacidade necessárias para concluir as atividades designadas dentro das restrições do projeto. Se os membros da equipe do projeto não têm as competências necessárias, o desempenho do projeto pode ser GEPROS. Gestão da Produção, Operações e Sistemas, v. 15, nº 1, p. 129 - 150, 2020. 
Análise do perfil de competências obtido em cursos de graduação em ciências da vida e o perfil de competências esperado do profissional de projetos

prejudicado. Quando essas incompatibilidades são identificadas, respostas proativas tais como treinamento, contratação, mudanças de cronograma ou mudanças de escopo são iniciadas.

Mesly (2015) salientou que a distância física entre participantes de um projeto internacional exige determinadas habilidades chave por parte do gerente de projetos tais como: confiabilidade, capacidade para cooperar e engajamento. Destaca-se também que o idioma e a cultura constituem obstáculos à comunicação entre as partes.

Neste sentido, Ziek e Anderson (2015) enfatizam que a comunicação é um meio de criação que modela não somente o escopo do projeto, mas também sua trajetória. A comunicação, segundo eles, dá aos gerentes de projetos outra forma de controle - outra ferramenta para desenhar os objetivos, atividades e recursos predeterminados de um projeto.

\subsection{Competências para profisssões da área de ciências da vida}

Epstein e Hundert (2002) propuseram a seguinte definição para competência profissional na área médica: o uso habitual e sensato da comunicação, conhecimento, habilidades técnicas, racional médico, emoções, valores e reflexões na prática diária para o benefício do indivíduo e comunidade a qual ele está servindo. Segundo os mesmos autores, a competência é construída sobre habilidades clínicas básicas, conhecimento científico, desenvolvimento moral, capacidade de integração, de reagir apropriadamente segundo o contexto no qual está inserido o problema e ser capaz de conhecer as próprias limitações.

Hallworth et al. (2002) identificaram alguns papéis dos cientistas clínicos, entre eles, manter bases científicas do serviço, exercer a prática clínica, dar conselhos científicos e diagnósticos, gerenciar e auditar técnicas científicas, desenvolver, avaliar e fornecer novos serviços, conduzir e direcionar pesquisa e desenvolvimento, ensinar profissionais de laboratório e outros profissionais de saúde, desenvolver e manter padrões de qualidade, e finalmente participar de auditorias clínicas.

Estes papéis podem ser divididos em competências científicas, competências clínicas, competências técnicas e de pesquisa científica, além da competência para desenvolver habilidades de resolver problemas e competências gerenciais. Segundo Hallworth et al. (2002), apesar de o desenvolvimento e a manutenção de tais habilidades exigirem um investimento considerável por parte destes profissionais (tempo e dinheiro), este investimento é essencial para propiciar flexibilidade na estrutura de carreira. 
Análise do perfil de competências obtido em cursos de graduação em ciências da vida e o perfil de competências esperado do profissional de projetos

Neste sentido, Beukers (2010) salientou a necessidade de treinamentos para as habilidades de gestão de projetos na área de ciências da vida, tais como: comunicação pessoal, motivação de equipe, liderança não autoritária, monitoramento, foco no processo e não no conteúdo, e planejamento.

Conforme destacam Jones et al. (2012) as responsabilidades atribuídas aos profissionais da área de pesquisa clínica vêm aumentando substancialmente, em parte devido a um aumento da complexidade dos protocolos clínicos, acompanhado de uma expansão global do desenvolvimento de produtos farmacêuticos, e que tal fato aumentou a demanda por profissionais formados e treinados nos países em desenvolvimento.

As competências comuns às áreas de pesquisa clínica e desenvolvimento de medicamentos são: agir de maneira responsável e ética durante a condução da pesquisa, conhecer conceitos científicos e os princípios de desenho dos estudos, possuir um senso crítico e analítico diante das informações disponíveis (literatura científica e dados clínicos obtidos), ser capaz de operacionalizar um estudo clínico, bem como conhecer e obedecer aos prazos da legislação global e local, gerenciar o "site" de pesquisa e os dados obtidos, liderança, gestão de negócios, comunicação, e trabalho em equipe (JONES et al., 2012).

A fim de elaborar um programa de treinamento para os médicos farmacêuticos e cientistas desenvolvedores de drogas, Silva et al. (2013) investigaram a competências essenciais para estes profissionais. Eles citam um conjunto de 7 competências essenciais para estes profissionais: 1) identificar necessidades terapêuticas ainda não atendidas pela indústria farmacêutica, 2) planejar, avaliar e confirmar resultados clínicos, bem como elaborar relatórios para submissão às autoridades regulatórias e artigos científicos para publicação, 3) interpretar os requisitos das autoridades para aprovação de uma nova droga, 4) avaliar e escolher a melhor ferramenta para minimizar os riscos da drogas, a fim de mantê-la no mercado, 5) combinar ética dos negócios e nos princípios utilizados nos estudos clínicos, 6) avaliar de modo ético as atividades de negócio da companhia de modo a garantir o bem estar do paciente , 7) praticar liderança, gerenciamento de pessoas, exercer influência sobre as partes interessadas, e alcançar objetivos científicos e de negócios.

Em estudo posterior, Silva et al. (2014) verificaram quais seriam necessidades educacionais dos profissionais envolvidos na área de pesquisa clínica. Além do conhecimento técnico acadêmico, também foi considerado importante desenvolver habilidades para gestão de negócios. Silva et al. (2014) ressaltaram que as habilidades de gestão de negócios e de GEPROS. Gestão da Produção, Operações e Sistemas, v. 15, nº 1, p. 129 - 150, 2020 
Análise do perfil de competências obtido em cursos de graduação em ciências da vida e o perfil de competências esperado do profissional de projetos

relacionamento interpessoal, consideradas mais importantes foram: habilidades para comunicação e apresentação, liderança, trabalho em grupo, orientação de colegas, negociação, escrita médica, desenvolvimento de network, gestão e resolução de conflitos, comunicação interpessoal com o time, poder de tomada de decisão, planejamento do projeto, gestão de crises, gestão de pessoas (RH), gestão financeira, e gestão de tempo e estresse.

\section{PROCEDIMENTOS METODOLÓGICOS}

\subsection{Percepção dos profissionais de projetos quanto ao perfil de competências essenciais} de um profissional desta área

O presente trabalho teve por objetivo traçar o perfil esperado de um profissional que atue em projetos (execução, participação e/ou gestão) sob a perspectiva dos profissionais envolvidos em gestão de projetos da indústria farmacêutica e life science, provenientes de diversos departamentos. Para tanto, o trabalho adotou o estudo de casos como abordagem metodológica, seguindo Yin (2001) e Eisenhardt (1989). A escolha desta metodologia é justificada pelo fato de o investigador não ter controle sobre os eventos, e o contexto ser relevante e atual. Os dados foram obtidos por meio de entrevistas feitas com gerentes de projetos de diferentes departamentos dentro da indústria farmacêutica. Com base na revisão de literatura foi elaborado um roteiro de perguntas para as entrevistas de modo a investigar qual a formação inicial, quais competências possuíam inicialmente, traçar as trajetórias destes profissionais ao longo da carreira, quais as competências para gestão de projetos tiveram que desenvolver, e qual a impressão deles em relação aos profissionais ingressantes na indústria farmacêutica, no que se refere ao exercício do trabalho em projetos.

\subsubsection{Perfil das empresas de origem dos entrevistados}

- 2 da empresa I: empresa multinacional, com matriz alemã, e com 39.000 colaboradores, está entre as 10 maiores corporações de especialidades farmacêuticas;

- 1 da empresa II: laboratório farmacêutico 100\% brasileiro, fundado em 1966, com 4.500 colaboradores;

- 1 da empresa III: laboratório farmacêutico $100 \%$ brasileiro. Fundado há 58 anos, e com 2500 colaboradores;

- 1 da empresa IV: empresa da área life science, parte de uma holding multinacional com sede em Washington, fundada nos anos 80, e com 63000 empregados; 
Análise do perfil de competências obtido em cursos de graduação em ciências da vida e o perfil de competências esperado do profissional de projetos

- 1 da empresa V: empresa nacional de consultoria da área de TI, com menos de 50 funcionários;

3.2 Perfil de competências obtidos pelos profissionais da área de ciências da vida comumente contratados pela indústria farmacêutica durante o curso de graduação.

O objetivo secundário foi realizar uma análise qualitativa do perfil de competências alcançado durante o curso de graduação de profissões da área de ciências da vida cujos profissionais são comumente contratados pela indústria farmacêutica, tais como: biomedicina, ciências biológicas, enfermagem, farmácia, medicina veterinária, odontologia e medicina. Para tanto, foi utilizada a metodologia de análise conteúdo das diretrizes curriculares do MEC (2018) para estas carreiras. Esta metodologia é justificada por proporcionar um levantamento de indicadores (quantitativos ou não) e que podem levar a inferências de conhecimentos (OLIVEIRA, 2008; BARDIN, 2011).

\subsection{Comparação entre o perfil de competências dos profissionais da área de ciências da} vida e do profissional de projetos.

Após a obtenção da análise do perfil de competências esperadas ao fim do curso de graduação dos profissionais da área de ciências da vida e uma análise do perfil esperado destes profissionais para que possam atuar em projetos segundo a percepção dos profissionais da área, foi realizada um comparativo entre os dois perfis.

\section{RESULTADOS E DISCUSSÕES}

\subsection{Percepção dos gerentes de projetos quanto ao perfil de competências essenciais de um profissional de projetos}

Os seis entrevistados (caracterizados no Quadro 1) foram unânimes em afirmar que trabalhar com projetos é uma tendência dentro dos departamentos onde atuam, confirmando o observado por Crawford (2005), para quem a gestão de projetos tem crescido como uma prática cada vez mais usada pelas organizações para atingir seus objetivos de negócios. O entrevistado B salientou que embora o termo projeto não seja utilizado na empresa onde atua, existem trabalhos que possuem escopo, orçamento pré-determinado, prazos, e necessitam de 
Análise do perfil de competências obtido em cursos de graduação em ciências da vida e o perfil de competências esperado do profissional de projetos

gestão de recursos, e que, portanto, poderiam ser considerados como projetos. Para a entrevistada E, a gestão de projetos como prática para se alcançar objetivos de negócios, remete a ideia de inovação, e que isso implica em trabalhar com projetos. Para os entrevistados A e F, que trabalham no departamento de farmacovigilância, a rotina de trabalho não envolve projetos, mas eles acreditam que sim, é uma tendência, e que para profissionais de outros departamentos da empresa já se trata de uma rotina comum. É interessante notar que, embora a área de atuação dos entrevistados seja bastante diversa (A $\mathrm{e} F$ : farmacovigilância; B: vendas e assessoria científica no pós-venda; C: analista de TI; D: prospecção de novas moléculas; E: analista de um PMO), todos já utilizaram, tiveram contato, ou precisaram dos conhecimentos de gestão de projetos.

Quadro 1 - Caracterização dos profissionais entrevistados.

\begin{tabular}{|c|c|c|c|c|c|c|}
\hline Entrevistado & $\begin{array}{c}\text { Empresa/ } \\
\text { tempo (anos) }\end{array}$ & $\begin{array}{c}\text { Idade } \\
\text { (anos) }\end{array}$ & Gênero & Formação & $\begin{array}{c}\text { Pós- } \\
\text { graduação }\end{array}$ & $\begin{array}{c}\text { Cargo } \\
\text { de } \\
\text { gerente }\end{array}$ \\
\hline A & I/5 & 34 & M & Medicina & Residência & Sim \\
\hline B & IV/6 & 37 & M & Odontologia & Mestrado & Sim \\
\hline C & V/2 & 41 & F & Farmácia & $\begin{array}{c}\text { Mestrado e } \\
\text { Doutorado }\end{array}$ & Não \\
\hline D & III/5 & 38 & F & Farmácia & Doutorado & Sim \\
\hline E & II/3 & 29 & F & Farmácia & $\begin{array}{c}\text { MBA em } \\
\text { Gestão de } \\
\text { Projetos }\end{array}$ & Não \\
\hline F & I/7 & 41 & F & Medicina & Residência & Sim \\
\hline
\end{tabular}

Fonte: Autores (2018).

Os seis entrevistados trabalham com projetos. Aqueles que possuem uma pósgraduação stricto senso (mestrado ou doutorado) afirmam ter trabalhado com projetos durante rotina de pesquisas científicas. Os demais afirmam ter tido o primeiro contato com projetos ao entrarem para o mundo corporativo das indústrias. Em muitos casos, tais atividades não eram denominadas projetos, mas sempre envolviam objetivo de curto prazo, cronogramas, e gestão de recursos, citam como exemplo: implementação de serviços terceirizados no departamento, de novos treinamentos, e implantação de novas ferramentas de trabalho.

De todos os entrevistados, com exceção da entrevistada E que cursou um MBA em Gestão de Projetos, e do entrevistado B que afirma receber treinamentos internos nesta área, os demais declaram não terem recebido treinamento ou preparo para trabalhar com gestão de 
Análise do perfil de competências obtido em cursos de graduação em ciências da vida e o perfil de competências esperado do profissional de projetos

projetos, e que os conhecimentos foram adquiridos por meio da experiência. Nos casos dos entrevistados A e F, conhecimentos das ferramentas de gestão de projetos foram exigidos durante a execução de um projeto envolvendo várias interfaces globais do departamento sem que tivessem preparo prévio para tal. No caso destes dois entrevistados em particular, para cujos departamentos o trabalho com projetos não faz parte da rotina, o conhecimento em gestão de projetos poderia ter facilitado e agilizado a aceitação e o andamento do projeto. No caso da entrevistada D, a empresa conta com um PMO que a auxilia quanto ao uso das ferramentas de gestão de projetos.

O tamanho dos projetos varia bastante. No caso da entrevistada D, ela é considerada uma gerente de projetos, mas atua a distância, acompanhando projetos de startups no exterior e fazendo a prospecção de novas oportunidades de negócios para a empresa, não sabe com exatidão quantas pessoas estão envolvidas nos projetos. Os projetos dos entrevistados A e F variam bastante de tamanho, usualmente são de pequeno (até 40 pessoas) a médio porte (até 150 pessoas) e são voltados para a implantação de novos sistemas e ferramentas de métrica, sendo que os de grande porte não são uma rotina no departamento. A entrevistada $\mathrm{F}$, gostaria que os projetos fossem uma rotina, pois na opinião dela, desenvolvem o espírito crítico e a capacidade de aceitar mudanças de maneira positiva.

Devido à natureza do trabalho, a entrevistada $\mathrm{F}$ não acredita que seja viável a implantação de um PMO dentro do departamento. A e F atualmente participam de um projeto global que envolve várias subáreas de farmacovigilância, e para este projeto foi contratado um PMO (consultoria externa). O entrevistado B não trabalha com PMO, mas todas as action plans tem que ser enviadas a matriz que avalia a sua viabilidade, se foi solicitado dentro dos padrões da empresa, se estão sendo cumpridas dentro do prazo e dentro do orçamento, e conclui que a matriz funciona como um PMO. A entrevistada E, trabalha em um PMO e acompanha os projetos de novos negócios da empresa, desde a prospecção até mesmo a instalação de plantas para produção de medicamentos.

Somente para as colaboradoras D e B, cujas atividades requerem um conhecimento técnico sólido, a formação acadêmica (graduação) tem um peso fundamental. Para os demais entrevistados, o brilhantismo na graduação não necessariamente implica no sucesso profissional, isso vai depender muito mais de como o indivíduo vai aplicar as ferramentas aprendidas. 
Análise do perfil de competências obtido em cursos de graduação em ciências da vida e o perfil de competências esperado do profissional de projetos

Quanto a familiaridade com as ferramentas de gestão de projetos, todos concordam que, entre os profissionais da área de ciências da vida, estes conhecimentos só são adquiridos após a graduação, e que eventualmente, alguns profissionais da área de farmácia e biólogos com formação stricto senso parecem ter alguma familiaridade. Tal afirmação parece confirmar os dados obtidos por Monteiro, Almeida Junior e Wajnzstejn (2014), nos quais os pesquisadores afirmaram não ter conhecimento sobre as ferramentas de gestão de projetos propriamente ditas, entretanto eles possivelmente possuem características de potenciais gerentes de projetos tais como identificar riscos e os impactos de suas decisões. A maioria dos entrevistados relata que passaram a ter contato com estas ferramentas por meio da vivência com projetos. Tal cenário parece não ser exclusividade dos profissionais da área de ciências da vida, Edum-Fotwe e McCaffer (2000) ao investigarem o desenvolvimento das competências do gerente de projetos sob a perspectiva da indústria da construção, observaram que grande parte do conhecimentos e habilidades em gestão de projetos são adquiridos por meio da experiência.

Os entrevistados A e B afirmam que devido à natureza da atividade de algumas carreiras, tópicos sobre gestão são ministrados durante a graduação, o que poderia facilitar o trabalho durante a carreira profissional. O entrevistado B citou como exemplo a engenharia, onde os profissionais parecem ter uma familiaridade maior com a rotina do trabalho com projetos do que profissionais de outras carreiras.

Para a maioria dos entrevistados, ao escolherem profissionais para participarem de um determinado projeto, são levados em consideração os conhecimentos do profissional (acadêmicos e de experiência profissional) que poderão ser úteis ao projeto. Outro ponto levado em consideração é o aspecto comportamental. A entrevistada E, explicou que dependendo do escopo do projeto, por exemplo, em projetos que tenham como escopo mudanças de processos dentro do departamento, questiona-se o quanto vale escolher pessoas resistentes às mudanças e que não desafiem o status quo. Destacou ainda, que é mais interessante colocar na equipe de projeto, pessoas cujas competências sejam complementares e não semelhantes. Tais observações corroboram as afirmações de Dreyfus (2008) para quem os conhecimentos técnicos são um importante parâmetro para a contratação de gerentes da área de pesquisa e desenvolvimento, entretanto somente estes não são suficientes, sendo necessário também desenvolver as habilidades interpessoais. 
Análise do perfil de competências obtido em cursos de graduação em ciências da vida e o perfil de competências esperado do profissional de projetos

Foram citadas como competências importantes para integrar uma equipe de projeto: formação acadêmica, capacidade de interagir com pessoas, flexibilidade, comunicação, gestão de conflitos, liderança, contextualização e engajamento.

Os entrevistados foram questionados quanto ao tipo de competências de gestão de projetos que julgam fundamentais. Comunicação efetiva foi citada por 4 dos entrevistados, tal competência também foi tema de estudo para Ziek e Anderson (2015) que enfatizaram o fato de a comunicação ser um meio de criação que modela não somente o escopo do projeto, mas também sua trajetória.

A contextualização foi citada por 3 dos entrevistados, incluindo a entrevistada E, para quem essa competência ainda é um problema para os colaboradores de seu departamento. Relacionamentos e gestão de stakeholders foram citados por 2 dos entrevistados. Inteligência emocional foi citada apenas pelo entrevistado B e gestão de conflitos apenas pelo entrevistado D.

Gestão de projetos globais também foi um tema abordado nesta pesquisa. Os entrevistados B e E não responderam pelo fato de trabalharem apenas com times locais. Comunicação voltou a ser unânime entre os entrevistados. Entretanto, com times globais, para que haja uma comunicação efetiva é necessário também que as partes entendam as diferenças culturais. Para times globais a cooperação é muito importante segundo a entrevistada D, principalmente se este projeto for de longo prazo. Mesly (2015) encontrou dados semelhantes e entre as habilidades necessárias para trabalhar com equipes globais, o autor cita: liderança, transparência, capacidade para inspirar confiança, senso de justiça, capacidade de cooperar e dividir informações, e comprometimento. O mesmo autor ainda comenta que o idioma e a cultura constituem obstáculos adicionais à comunicação entre as partes.

Quanto às competências comportamentais foram citadas negociação, gestão de stakeholders, gestão de conflitos, inteligência emocional para lidar com pressões, pensamento crítico, comunicação, auto aprimoramento, trabalho em equipe, liderança, flexibilidade e eficiência. Das competências associadas a gestão de projetos foram citadas gestão de stakeholders, controle, organização, planejamento, comunicação e mudanças.

Todos concordam que um treinamento (interno ou externo) para as ferramentas de gestão de projetos seria interessante, uma vez que a demanda por tal tipo de trabalho vem aumentando e os colaboradores, em geral, não possuem conhecimento e/ou não estão familiarizados com estas ferramentas. Segundo o entrevistado A, treinamentos poderiam GEPROS. Gestão da Produção, Operações e Sistemas, v. 15, nº 1, p. 129 - 150, 2020 
Análise do perfil de competências obtido em cursos de graduação em ciências da vida e o perfil de competências esperado do profissional de projetos

ajudar o profissional a contextualizar, a perceber o impacto de suas decisões para o resto da companhia. A entrevistada E, complementa afirmando que para a real efetividade desses treinamentos, seria necessário preparar os colaboradores no sentido de mostrar a eles a razão, o porquê de o curso estar sendo ministrado.

No Quadro 2 estão listadas as competências esperadas de um profissional de projetos, seja como gestor ou como membro da equipe, citadas pelos entrevistados, e classificadas segundo as categorias propostas pelo IPMA (2006).

Quadro 2 - Competências citadas pelos entrevistados.

\begin{tabular}{|ccc|}
\hline Comportamentais & Técnicas & Contextuais \\
\hline Relacionamento interpessoal & Conhecimento acadêmico & Contextualização \\
Flexibilidade & Gestão de stakeholders & \\
Liderança & Controle & \\
Engajamento/Comprometimento & Planejamento & \\
Trabalhar com diferenças culturais & Gestão de mudanças & \\
Inteligência emocional & Comunicação & \\
(trabalhar sob pressão) & & \\
Cooperação & Trabalho em equipe & \\
Auto aprimoramento & \\
Pensamento crítico & \\
Eficiência & \\
\hline
\end{tabular}

Fonte: Autores (2018).

\subsection{Análise das competências esperadas ao fim do curso de graduação dos alunos}

Foram analisadas as diretrizes dos cursos de graduação de profissões da área de ciências da vida cujos profissionais são comumente contratados pela indústria farmacêutica: biomedicina, ciências biológicas, enfermagem, farmácia, medicina veterinária, odontologia e medicina. As diretrizes dos cursos de graduação analisadas nesta pesquisa foram publicadas entre os anos de 2001 e 2003, com exceção das diretrizes para a carreira de medicina que foi publicada em 2014.

Hallworth et al. (2002) afirmaram que além do conhecimento técnico-científico é necessário que o cientista clínico desenvolva também outras habilidades a fim de propiciar flexibilidade na estrutura de carreira e estabelecer os mecanismos para a transferência entre diferentes cargos ou ampliar a gama de funções que pode assumir. Neste trabalho, foram analisadas competências descritas nas diretrizes dos cursos de graduação da área de ciências da vida e que poderiam influenciar a capacidade do indivíduo para trabalhar com projetos, não somente como gestor, mas também como integrante de uma equipe de projetos. 
Análise do perfil de competências obtido em cursos de graduação em ciências da vida e o perfil de competências esperado do profissional de projetos

O gráfico apresentado na Figura 3 mostra em quantas diretrizes cada uma das 14 competências foi encontrada.

Figura 3 - Número de diretrizes que citam as competências associadas ao trabalho com projetos.

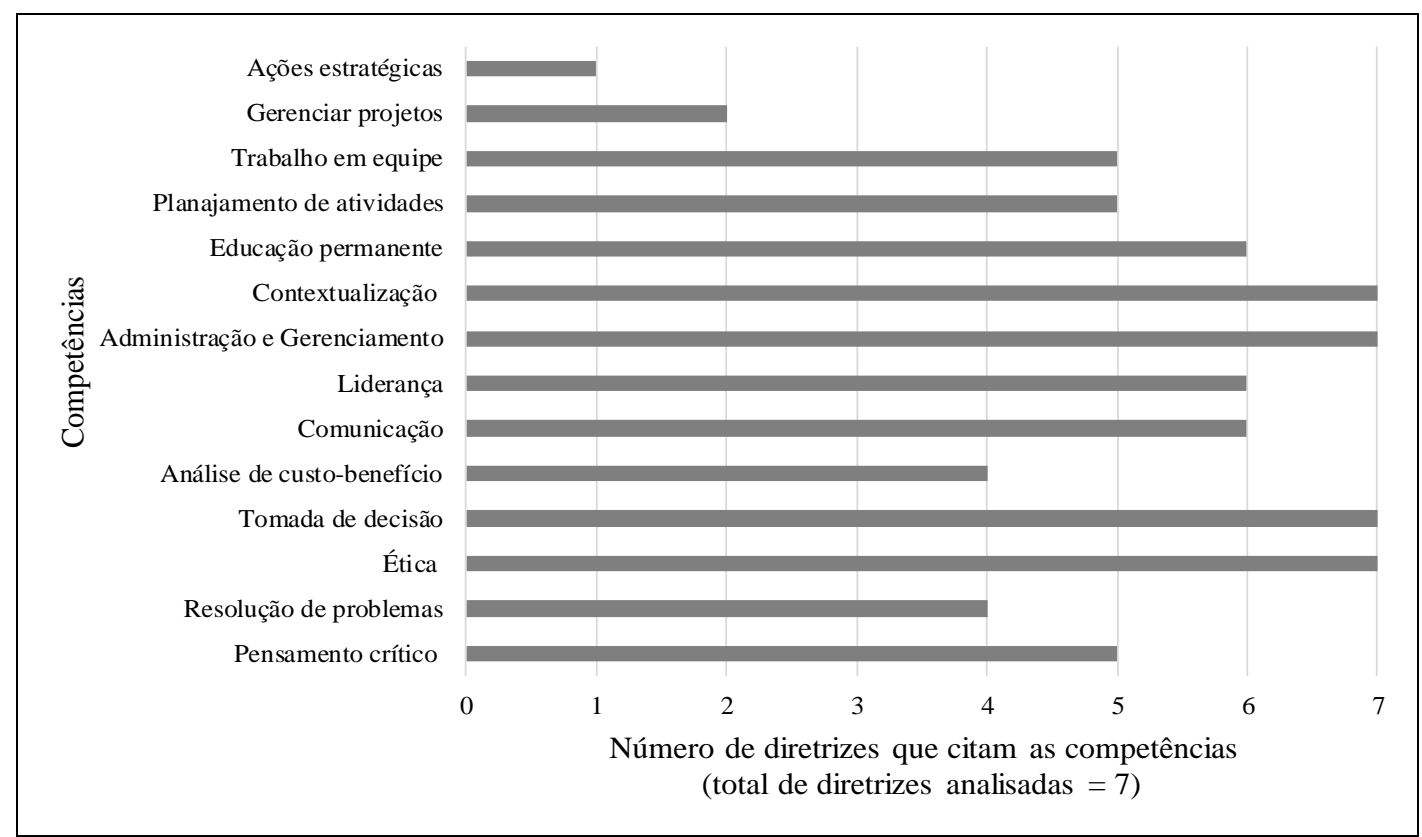

Fonte: Autores (2018).

A análise das diretrizes revelou uma uniformidade no que se refere às habilidades a serem desenvolvidas durante o curso de graduação, e que poderiam ser aplicadas ao trabalho envolvendo projetos, são elas: ética, capacidade de tomada de decisão, administração e gerenciamento, e contextualização. Das 14 competências identificadas nas diretrizes, a carreira de ciências biológicas foi a que apresentou um menor número de competências em comum com a gestão de projetos, somente 7. Foram elas: ética, tomada de decisão, administração e gerenciamento, contextualização, e gerenciamento de projetos propriamente dito.

A análise do custo/risco versus benefício foi citada apenas para as carreiras de biomedicina, enfermagem, farmácia e odontologia. Apesar de tal observação, é preciso salientar que esta é uma habilidade que poderia ser desenvolvida no contexto de administração e gerenciamento. 
Análise do perfil de competências obtido em cursos de graduação em ciências da vida e o perfil de competências esperado do profissional de projetos

O gerenciamento de projeto propriamente dito foi citado nas diretrizes de apenas 3 carreiras: veterinária, medicina e ciências biológicas. Participar de ações estratégicas foi citado em apenas uma das diretrizes, veterinária.

Silva et al. (2013) citam um conjunto de 7 competências essenciais para os profissionais de ciências da vida, entre as quais, 3 foram encontradas durante a análise das diretrizes no presente trabalho: 1) ser capaz de combinar ética dos negócios e nos princípios utilizados nos estudos clínicos (no presente estudo denominado ética); 2) praticar liderança, gerenciamento de pessoas, exercer influência sobre as partes interessadas, e 3) alcançar objetivos científicos e de negócios (no presente estudo interpretado como liderança). O Quadro 3 mostra a distribuição das competências nas diretrizes segundo a carreira.

Quadro 3 - Distribuição das competências nas diretrizes segundo a carreira.

\begin{tabular}{|c|c|c|c|c|c|c|c|}
\hline 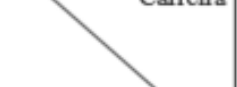 & Biomedicina & Enfermagem & Farmácia & Veterinária & Odontologia & Medicina & $\begin{array}{c}\text { Ciências } \\
\text { Biológicas }\end{array}$ \\
\hline Pensamento critico & $\mathrm{x}$ & & & $\mathrm{x}$ & $\mathrm{x}$ & $\mathrm{x}$ & $\mathrm{x}$ \\
\hline $\begin{array}{l}\text { Resolução de } \\
\text { problemas }\end{array}$ & $\mathrm{x}$ & $\mathrm{x}$ & & & $\mathrm{x}$ & $\mathrm{x}$ & \\
\hline Ética & $\mathrm{x}$ & $\mathrm{x}$ & $\mathrm{x}$ & $\mathrm{x}$ & $\mathrm{x}$ & $\mathrm{x}$ & $\mathrm{x}$ \\
\hline Tomada de decisão & $\mathrm{x}$ & $\mathrm{x}$ & $\mathrm{x}$ & $\mathrm{x}$ & $\mathrm{x}$ & $\mathrm{x}$ & $\mathrm{x}$ \\
\hline $\begin{array}{c}\text { Análise de custo- } \\
\text { beneficio }\end{array}$ & $\mathrm{x}$ & $\mathrm{x}$ & $\mathrm{x}$ & & $\mathrm{x}$ & & \\
\hline Comunicação & $\mathrm{x}$ & $\mathrm{x}$ & $\mathrm{x}$ & $\mathrm{x}$ & $\mathrm{x}$ & $\mathrm{x}$ & \\
\hline Liderança & $\mathrm{x}$ & $\mathrm{x}$ & $\mathrm{x}$ & $\mathrm{x}$ & $\mathrm{x}$ & $\mathrm{x}$ & \\
\hline $\begin{array}{l}\text { Administração e } \\
\text { Gerenciamento }\end{array}$ & $\mathrm{x}$ & $\mathrm{x}$ & $\mathrm{x}$ & $\mathrm{x}$ & $\mathrm{x}$ & $\mathrm{x}$ & $\mathrm{x}$ \\
\hline Contextualização & $\mathrm{x}$ & $\mathrm{x}$ & $\mathrm{x}$ & $\mathrm{x}$ & $\mathrm{x}$ & $\mathrm{x}$ & $\mathrm{x}$ \\
\hline $\begin{array}{l}\text { Educação } \\
\text { permanente }\end{array}$ & $\mathrm{x}$ & $\mathrm{x}$ & $\mathrm{x}$ & $\mathrm{x}$ & $\mathrm{x}$ & $\mathrm{x}$ & \\
\hline $\begin{array}{l}\text { Planejamento de } \\
\text { atividades }\end{array}$ & & $\mathrm{x}$ & $\mathrm{x}$ & $\mathrm{x}$ & $\mathrm{x}$ & $\mathrm{x}$ & \\
\hline Trabalho em equipe & $\mathrm{x}$ & $\mathrm{x}$ & $\mathrm{x}$ & & $\mathrm{x}$ & $\mathrm{x}$ & \\
\hline Gerenciar projetos & & & & $\mathrm{x}$ & & $\mathrm{x}$ & $\mathrm{x}$ \\
\hline Ações estratégicas & & & & & & & $\mathrm{x}$ \\
\hline
\end{tabular}

Fonte: Autores (2018). 
Análise do perfil de competências obtido em cursos de graduação em ciências da vida e o perfil de competências esperado do profissional de projetos

\subsection{Comparação entre o perfil de competências dos profissionais da área de ciências da vida e do profissional de projetos na indústria farmacêutica.}

Esta comparação foi baseada nas análises das diretrizes para os cursos de graduação da área de ciências da vida apresentadas no item 4.2. Para cada uma das competências, foram verificadas em quantas diretrizes elas foram citadas (total de 14 competências e um total de 7 diretrizes analisadas). Outras competências citadas pelos entrevistados foram adaptação, comportamento, cooperação, capacidade entender as diferenças culturais e trabalhar com elas, inteligência emocional, capacidade de trabalhar com prazos, organização, controle, saber relacionar-se com outras pessoas e gestão de stakeholders.

Para observar visualmente a comparação foi elaborado um gráfico radar (Figura 4), onde as competências citadas pelos entrevistados aparecem circundadas em vermelho.

Figura 4 - Comparação entre as competências citadas nas diretrizes e as citadas pelos entrevistados.

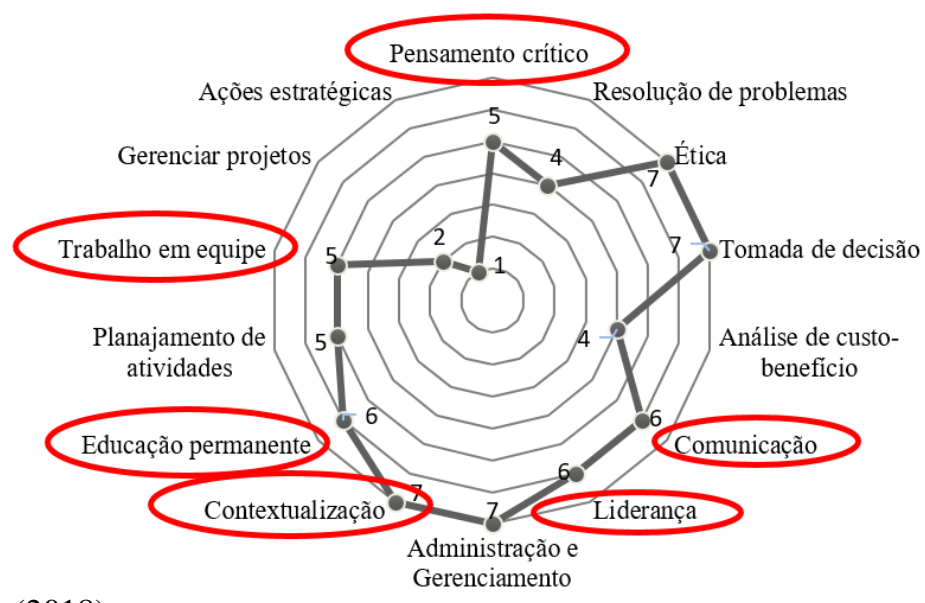

Fonte: Autores (2018).

Apesar das diretrizes estabelecerem que algumas das competências descritas pelos profissionais de projetos devam ser desenvolvidas durante os cursos de graduação, é necessário salientar que os entrevistados declararam não terem recebido conhecimentos sobre gestão de projetos durante a graduação. As empresas da área farmacêutica geralmente promovem profissionais da área de ciências da vida à cargos de gestão, incluindo gestão de projetos.

GEPROS. Gestão da Produção, Operações e Sistemas, v. 15, nº 1, p. 129 - 150, 2020. 
Análise do perfil de competências obtido em cursos de graduação em ciências da vida e o perfil de competências esperado do profissional de projetos

Se por um lado, estes profissionais são importantes para a equipe ou a organização, por outro lado eles não possuem as competências para gestão de projetos e não manifestam disposição para desenvolvê-las. Por esta razão, é que a empresa, dos entrevistados A e F, parece ter optado por terceirizar a gestão de projetos. A falta de familiaridade com trabalhos envolvendo projeto, incluindo tanto os conhecimentos teóricos como as competências comportamentais (soft skills), pode ter impacto não somente sobre a colocação do profissional recém-formado no mercado de trabalho, como também, sobre a adaptação dos mesmos às rotinas envolvendo atividades em projetos. Além disso, gastos com treinamentos poderiam ser evitados, um melhor planejamento seria obtido e, o retrabalho poderia ser menor.

\section{CONCLUSÕES}

Os objetivos da pesquisa foram analisar o perfil de competências esperado dos profissionais de projetos com formação na área de ciências da vida sob a perspectiva de gerentes e profissionais de projetos atuando em diversas áreas e mapear as competências associadas à gestão de projetos esperadas dos profissionais da área de ciências da vida ao final do curso de graduação.

Com base nos dados obtidos, foi possível concluir que embora as diretrizes estabeleçam que algumas das competências que podem ter impacto nos trabalhos envolvendo projetos devam ser desenvolvidas durante o curso de graduação, isso não parece corresponder a realidade, uma vez que todos os profissionais entrevistados declararam não terem adquirido os conhecimentos sobre tais assuntos durante a graduação, e sim por meio de cursos de pósgraduação ou por meio da experiência profissional.

A principal contribuição deste trabalho é evidenciar a importância de preparar os alunos de graduação das áreas de ciências da vida para o trabalho em projetos, de forma a ampliar a área de atuação destes profissionais, pois esta forma de trabalho é uma tendência cada vez mais evidente nas corporações nos dias atuais. Além disso, alerta para distância que existe entre o que é proposto pelas diretrizes dos cursos de graduação e o que realmente é ministrado ao aluno de graduação na área de ciências da vida.

Esta pesquisa apresenta limitações, uma vez que as entrevistas foram realizadas com profissionais com formação na área de ciências da vida, por isso é possível que os resultados contidos neste trabalho não reflitam a realidade em outros segmentos de mercado. Como 
Análise do perfil de competências obtido em cursos de graduação em ciências da vida e o perfil de competências esperado do profissional de projetos

sugestão para futuras pesquisas, pode-se focar em obter um perfil do recém-formado da área de ciências da vida de modo a traçar um perfil mais detalhado de suas competências sob a perspectiva dele próprio, e compará-lo aos perfis de outras áreas do conhecimento.

\section{Referências}

AHSAN, K.; HO, M.; KHAN, S. Recruiting Project Managers: A Comparative Analysis of Competencies and Recruitment Signals from Job Advertisements. Project Management Journal, v. 44, n. 5, p. 36-54, 2013.

BARDIN, L. Análise de Conteúdo. Tradução de Rego, L.A. e Pinheiro, A. Lisboa: Edições 70, 2011.

BEUKERS, M. W. Project management of life-science research projects: project characteristics, challenges and training needs. Drug Discovery Today, v. 16, n. 3-4, p. 93-98, 2010.

CHIOCCHIO, F.; RABBAT, F.; LEBEL, P. Multi-level efficacy evidence of a combined interprofessional collaboration and project management training program for healthcare project teams. Project Management Journal, v. 46, n. 4, p. 20-34, 2015.

CLEMENTS, J. P.; GIDO, J. Gestão de Projetos. Tradução de EZ2 TRANSLATE. São Paulo: Cengage Learning, 2013.

CRAWFORD, L. Senior management perceptions of Project management competence. International Journal of Project Management, v. 23, n. 1, p.7-16, 2005.

DAINTY, A. J.; ASCE, M.; CHENG, M.; MOORE, D. P. Competency-based model for predicting construction project managers' performance. Journal of Management in Engineering, v. 21, n. 1, p. 2-9, 2005.

DREYFUS, C. R. Identifying competencies that predict effectiveness of R\&D managers. Journal of Management Development, v. 27, n. 1, p. 76-91, 2008.

EDUM-FOTWE, F.T.; McCAFFER, R. Developing project management competency: perspectives from the construction industry. International Journal of Project Management, v.18, n. 2, p. 111-124, 2000.

EISENHARDT, K.M. Building theories from case study research. Academy of Management Review, v.14, n. 4, p. 532-550, 1989.

EPSTEIN, R. M.; HUNDERT, E. M. Defining an assessing professional competence. JAMA, v. 287, n. 2, p. 226-235, 2002. 
Análise do perfil de competências obtido em cursos de graduação em ciências da vida e o perfil de competências esperado do profissional de projetos

GEOGHEGAN, L.; DULEWICZ, V. Do Project managers' leadership competencies contribute to project success? Project Management Journal, v. 39, n. 4, p.58-67, 2008.

HALLWORTH, M.; HYDE, K.; CUMMING, A.; PEAK, I. The future for clinical scientists in laboratory medicine. International Journal of Laboratory Hematology, v. 24, n. 4, 197 $204,2002$.

INTERNATIONAL PROJECT MANAGEMENT ASSOCIATION (IPMA). ICB - IPMA Competence Baseline, Version 3.0. Nijkerk: International Project Management Association, 2006.

JONES, C. T.; BROWNING, S.; GLADSON, B.; HORNUNG, C.; LUBEJKO, B. G.; PARMENTIER, J.; PIDD, H.; SILVA, H.; SONSTEIN, S. Defining competencies in clinical research: issues in clinical research education and training. Research Practitioner, v. 3, n. 2, 99-107, 2012.

MESLY, O. Exploratory findings on the influence of physical distance on six competencies in an international project. International Journal of Project management, v. 33, n. 7, p. 1425$1437,2015$.

MEC (MINISTÉRIO DA EDUCAÇÃO E CULTURA). Diretrizes curriculares - cursos de graduação. Disponível em: http://portal.mec.gov.br/conselho-nacional-de-educacao/atosnormativos--sumulas-pareceres-e-resolucoes?id=12991. Acesso em: 28 abr. 2018.

MONTEIRO, C. B. D. M.; ALMEIDA JUNIOR, Á. D. D.; WAJNZSTEJN, R. Project management in health and medical research. Journal of Human Growth and Development, v. 24, n. 3, p. 239-242, 2014.

MÜLLER, R.; TURNER, R. Leadership competency profiles of successful project managers. International Journal of Project Management, v. 28, n. 5, p. 437-448, 2010.

OLIVEIRA, D.C. Análise de conteúdo temático-categorial: uma proposta de sistematização. Revista de Enfermagem UERJ, v.16, n.4, p. 569-576, 2008.

OOSTERLINCK, A.; DEBACKERE, K.; CIELEN, G. Balancing basic and applied research. EMBO reports, v. 3, n. 1, p. 2-5, 2002.

PAYNE, J. M.; FRANCE, K. E.; HENLEY, N.; D'ANTOINE, H. A.; BARTU, A. E.; ELLIOTT, E. J. Researchers' experience with project management in health and medical research: Results from a post-project review. BMC Public Health, v. 11, n. 1, p. 424-435, 2011.

PROJECT MANAGEMENT INSTITUTE (PMI). Project manager competency development (PMCD) framework. 2nd. Ed. Newtown Square: Four Campus Boulevard, 2007. 
Análise do perfil de competências obtido em cursos de graduação em ciências da vida e o perfil de competências esperado do profissional de projetos

PROJECT MANAGEMENT INSTITUTE (PMI). Um guia do conhecimento em gerenciamento de projetos (guia PMBOK). 5. ed. ed. São Paulo: Saraiva, 2014.

ROSE, J.; PEDERSEN, K.; HOSBOND, J.H.; KRAEMMERGAARD, P. Management competences, not tools and techniques: A grounded examination of software management at WM-data. Information and Software Technology, v.49, n. 6, p.605-624, 2007.

SILVA, H.; SONIER, P.; BUHLER, F.; DESLYPERE, J. P.; CRISCUOLO, D.; NELL, G.; MASSUD, J.; GEARY, S.; SCHENCK, J.; KERPEL-FRONIUS, S.; KOSKI, G.; CLEMENS, N.; KLINGMANN, I.; KESSELRING, G.; VAN OLDEN, R.; DUBOIS, D. Core competencies for pharmaceutical physicians and drug development scientists. Frontiers in Pharmacology, v. 4, p. 1-8, 2013.

SILVA, H.; KESSELRING, G. F.; YRIVARREN, J. L.; MASSUD FILHO, J.; THOMSON, T. M.; SILVA, A.; SONSTEIN, S.; LIMA, M. V.; PULIDO, P. A. Education and training needs among clinical investigators and medicines development professionals from two latin american countries. Clinical Researcher, v. 28, n. 5, p. 18-25, 2014.

STEVENSON, D.H.; STARKWEATHER, J.A. PM critical competency index: IT execs prefer soft skill. International Journal of Project Management, v. 28, n. 7, p. 663-671, 2010.

THOMAS, J.; MENGEL, T. Preparing project managers to deal with complexity - Advanced project management education. International Journal of Project Management, v. 26, n. 3, p. 304-315, 2008.

VELHO, L.; RAMOS, M. Y. Formação de doutores no brasil: o esgotamento do modelo vigente frente aos desafios colocados pela emergência do sistema global de ciência. Avaliação, Campinas, Sorocaba, SP, v. 18, n. 1, p. 219-246, 2013.

YIN, R. K. Estudo De Caso - Planejamento E Métodos. 5. ed. Porto Alegre: Bookman Editora, 2001.

ZIEK, P.; ANDERSON, J. D. Communication, dialogue and project management. International Journal of Managing Projects in Business, v. 8, n. 4, p. 788-803, 2015. 